\title{
Anti-reflux surgery in lung transplant recipients: outcomes and effects on quality of life
}

\author{
A.G.N. Robertson*, A. Krishnan*, C. Ward", J.P. Pearson", T. Small ${ }^{\#}$, P.A. Corris" \\ J.H. Dark ${ }^{\#,+}$ D. Karat*, J. Shenfine* and S.M. Griffin*
}

ABSTRACT: Fundoplication may improve survival after lung transplantation. Little is known about the effects of fundoplication on quality of life in these patients. The aim of this study was to assess the safety of fundoplication in lung transplant recipients and its effects on quality of life.

Between June 1, 2008 and December 31, 2010, a prospective study of lung transplant recipients undergoing fundoplication was undertaken. Quality of life was assessed before and after surgery. Body mass index (BMI) and pulmonary function were followed up.

16 patients, mean \pm SD age $38 \pm 11.9$ yrs, underwent laparoscopic Nissen fundoplication. There was no peri-operative mortality or major complications. Mean \pm SD hospital stay was $2.6 \pm 0.9$ days. 15 out of 16 patients were satisfied with the results of surgery post fundoplication. There was a significant improvement in reflux symptom index and DeMeester questionnaires and gastrointestinal quality of life index scores at 6 months. Mean BMI decreased significantly after fundoplication $(p=0.01)$. Patients operated on for deteriorating lung function had a statistically significant decrease in the rate of lung function decline after fundoplication $(p=0.008)$.

Laparoscopic fundoplication is safe in selected lung transplant recipients. Patient benefit is suggested by improved symptoms and satisfaction. This procedure is acceptable, improves quality of life and may reduce deterioration of lung function.

KEYWORDS: Fundoplication, gastro-oesophageal reflux disease, lung transplantation

hronic microaspiration, secondary to extra-oesophageal reflux, may contribute to bronchiolitis obliterans syndrome (BOS) after lung transplantation. Up to $75 \%$ of lung transplant patients have demonstrable gastro-oesophageal reflux disease (GORD) [1-5]. Elevated biomarkers, pepsin and bile salts, have been documented in the bronchoalveolar lavage fluid after lung transplantation, suggesting microaspiration [6-8]. Early anti-reflux surgery may lead to protection of lung function and increased survival through preventing microaspiration. Most of the impetus has been from Duke University (Durham, NC, USA), where the majority of evidence originates [5]. There is a lack of basic information in this patient group, including safety and assessments of quality of life. Such information is important because physiological post-operative complications are common afetr fundoplication, and may lead to a reduction in quality of life, despite resolution of reflux symptoms. Specific complications include temporary dysphagia, nausea $[9,10]$, discomfort from gas bloating and increased flatulence [2]. Only one study has looked at the effects of fundoplication on quality of life in this population, despite a high prevalence of foregut dysfunction [11]. This puts these patients at risk of physiological dysfunction and reduced quality of life after surgery. To date, no transplant studies have been performed assessing the response of extra-oesophageal reflux symptoms to fundoplication.

The aim of this study was to assess the safety of fundoplication in lung transplant recipients and its effects on quality of life.

\section{METHODS}

A prospective study of all lung transplant recipients undergoing anti-reflux surgery between June 1, 2008 and December 31, 2010 at the Northern Oesophago-Gastric Unit (Royal Victoria Infirmary, Newcastle-upon-Tyne, UK) was carried out. All lung transplant recipients in this unit are routinely prescribed prophylactic proton pump inhibitor (PPI) therapy to prevent steroid-induced ulceration. There was no distinction in patient management made between underlying pathologies (e.g. cystic fibrosis). Surgery was considered for patients with symptomatic reflux alone, refractory to PPI

\section{AFFILIATIONS}

*Northern Oesophago-Gastric Unit, Royal Victoria Infirmary, \# Immunobiology and Transplantation Group, Institute of Cellular Medicine "Institute of Cellular and Molecular Biosciences, Newcastle University, and +Dept of Cardiothoracic Surgery, Freeman Hospital, Newcastle-uponTyne, UK.

\section{CORRESPONDENCE}

S.M. Griffin

Northern Oesophago-Gastric Unit Royal Victoria Infirmary Queen Victoria Road Newcastle-upon-Tyne NE1 4LP UK E-mail: michael.griffin@nuth.nhs.uk

Received:

April 082011

Accepted after revision: June 282011 First published online: July 202011 
therapy, or for reflux associated with deteriorating lung function. Patients with asymptomatic reflux were only considered for surgery if there were concerns about microaspiration. Maximal medical therapy was not considered for failed PPI therapy or suspected microaspiration, as it was felt that a mechanical barrier to reflux would better protect the allografts from microaspiration. Ethical approval for patient follow-up was obtained from a local ethics committee (County Durham and Tees Valley 2 Research Ethics Committee). Written consent was obtained for patients to be observed overall post lung transplant, but not specifically for this study.

Reflux status was assessed on PPI therapy by oesophageal manometry, $\mathrm{pH}$ impedance (Ohmega; $\mathrm{MMS}^{\mathrm{TM}}$, Utrecht, the Netherlands) and endoscopy. Patients underwent a thorough pre-operative assessment to ensure fitness for surgery. Reflux status was defined by the presence of oesophageal or extraoesophageal symptoms combined with objective evidence of GORD on $\mathrm{pH}$ impedance and/or endoscopy. Patients did not undergo a post-fundoplication $\mathrm{pH}$ impedance or endoscopic measurement of reflux status. Pulmonary function tests and bronchoscopy were routinely performed in the pre-operative work-up.

Patients were followed up clinically with emphasis on lung function, satisfaction with treatment and quality of life. The following questionnaires were used: the DeMeester Reflux Questionnaire, a validated standard reflux questionnaire; the Reflux Symptom Index (RSI) questionnaire, a validated laryngopharyngeal reflux questionnaire; and the Gastro-intestinal Quality of Life Index (GIQLI), a validated gastrointestinal-specific quality of life questionnaire [12-14]. These questionnaires covered oesophageal reflux symptoms (heartburn and dysphagia), extra-oesophageal reflux symptoms (cough and wheeze) and functional gastrointestinal symptoms that could be affected by fundoplication (bloating and flatus). These were assessed preand post-operatively. Pre- and post-fundoplication body mass index (BMI) were recorded. Patient satisfaction was assessed by direct questioning of patients.

Lung function was assessed in accordance with European Respiratory Society guidelines [15]. BOS scores were calculated using forced expiratory volume in $1 \mathrm{~s}$ (FEV1) in accordance with International Society for Heart and Lung Transplantation guidelines $[16,17]$. The rate of decline in FEV1 was calculated in accordance with previous studies, namely, the measures of FEV1 before fundoplication were plotted and the gradient between points from the baseline FEV1 level to the time fundoplication was calculated in millilitres per month. The same was done for the FEV1 measurements after fundoplication, the last FEV1 being either the current one in patients still alive or the final FEV1 in the patients who died [18].

In our unit, bronchoscopy is routinely performed at 1 week, and at 1,3 and 6 months, and $1 \mathrm{yr}$ post-transplant. Further bronchoscopies are carried out when clinically indicated by an unexplained drop in FEV1. Pulmonary function tests are carried out routinely at every outpatient visit, on average every 3 months.

The RSI, DeMeester reflux and GIQLI questionnaires were completed pre-operatively, and 6 weeks and 6 months postoperatively. The GIQLI score was subdivided into symptomatic questions $(n=17)$ and functional questions $(n=19)$ to assess whether changes in quality of life were due to changes in symptoms or social functioning. Patients were asked about overall satisfaction with the result of surgery at 6 weeks and 6 months post-operatively. Questionnaires were completed by patients, with expert advice on hand to explain any concerns about questions and to offer one-to-one advice.

\section{Surgical technique}

Laparoscopic Nissen fundoplication was performed. Access to the abdominal cavity was via four ports and an epigastric stab incision for the Nathanson retractor to retract the liver. Initially, the oesophageal hiatus was dissected to mobilise the oesophagus. The posterior vagus was preserved and a window was created behind the oesophago-gastric junction. The posterior crura were repaired to tighten the hiatus, and a loose $360^{\circ}$ wrap was tailored with three Ethibond ${ }^{\mathrm{TM}}$ sutures (Ethicon, Somerville, NJ, USA). One further suture was used to anchor the wrap to the oesophagus and right crus. Percutaneous endoscopic gastrostomy (PEG) fistulae were repaired when present. These were divided with an Endostapler ${ }^{\mathrm{TM}}$ device (Ethicon). The PEG wound was excised and the deficit in the abdominal wall and skin were closed. Local anaesthesia was inserted into the peritoneal cavity and infiltrated in the wounds at the end of the procedure.

Statistical analysis was carried out with the help of a statistician. Initially, a Kolmogorov-Smirnov test was performed to assess normality. Subsequently, paired t-tests and two-way ANOVAs were performed with a post-test Bonferroni correction. Figures were created using GraphPad Prism ${ }^{\mathrm{TM}}$ software (GraphPad, San Diego, CA, USA).

\section{RESULTS}

During the study period, 109 lung transplants were performed. 17 patients were considered for fundoplication. One patient was managed conservatively due to lack of objective evidence of GORD on $\mathrm{pH}$ impedance and endoscopy. Of 17 patients offered fundoplication, 16 (10 females and six males) with a mean \pm SD age of $38.2 \pm 11.9 \mathrm{yrs}$, consented to and underwent fundoplication. Indications for lung transplant were: cystic fibrosis in 10; chronic obstructive pulmonary disease (COPD)/asthma in one; COPD in one; pulmonary fibrosis in three; and pulmonary fibrosis/asthma in one patient. 13 patients underwent single sequential lung transplant, two had a right single lung transplant and one had a left single lung transplant. Indications for fundoplication were objective evidence of GORD on $\mathrm{pH}$ impedance and/or endoscopy with either typical reflux symptoms (heartburn) $(n=8)$ or typical (heartburn) and atypical extraoesophageal symptoms (cough and wheeze) with deteriorating lung function $(n=8)$. Symptoms occurred despite PPI therapy. Mean pre-operative $\mathrm{BMI} \pm \mathrm{SD}$ was $23.8 \pm 4.4 \mathrm{~kg} \cdot \mathrm{m}^{-2}$. Patient demographics are summarised in table 1 .

All patients had a diagnostic gastroscopy. 15 out of 16 patients had a hiatus hernia $(2-6 \mathrm{~cm})$. eight out of 16 has oesophagitis: grade $A, n=4$; grade $B, n=3$; and grade $C, n=1$. One patient had a small tongue of Barrett's oesophagus confirmed on histological assessment. Three patients had oesophageal candidiasis, which was treated pre-operatively. A summary of pre-operative oesophageal physiology is shown in table 2 . 


\section{TABLE 1 Demographics of study patients}

$\begin{array}{lc}\text { Age yrs } & 38.2 \pm 11.9 \\ \text { Sex } & \\ \text { Male } & 6 \\ \text { Female } & 10 \\ \text { Underlying pathology } & \\ \text { Cystic fibrosis } & 10 \\ \text { Pulmonary fibrosis } & 3 \\ \text { Pulmonary fibrosis/asthma } & 1 \\ \text { COPD } & 1 \\ \text { COPD/asthma } & 1 \\ \text { Transplant } & \\ \text { SSLT } & 13 \\ \text { LSLT } & 1 \\ \text { RSLT } & 2 \\ \text { BMI kg } \text { m }^{-2} & 23.8 \pm 4.4 \\ \text { FEV } 1 \text { L } & 2.4 \pm 0.97 \\ \text { FEV } 1 \% \text { pred } & 80 \pm 5 \\ \text { ASA } & \\ 2 & 5 \\ 3 & 11\end{array}$

Data are presented as mean \pm SD or $\mathrm{n}$. COPD: chronic obstructive pulmonary disease; SSLT: single sequential lung transplant; LSLT: left single lung transplant; RSLT: right single lung transplant; BMI: body mass index; FEV1: forced expiratory volume in $1 \mathrm{~s}$; \% pred: \% predicted; ASA: American Society of Anesthesiologists Physical Status classification.

\section{Operation}

Pre-operative American Society of Anaesthesiology score was 2 $(n=5)$ or $3(n=11)$. Mean \pm SD FEV1 was $80 \pm 5 \%$ predicted or FEV1 was $2.4 \pm 0.97$ L. Fundoplication was performed at a mean of $1,053 \pm 881$ days post-transplant.

Mean intra-operative time was $93 \pm 20 \mathrm{~min}$. All patients had blood loss of $<100 \mathrm{~mL}$. Four patients had a PEG fistula excised and no patients required an intensive treatment unit stay, although five out of 16 patients were admitted electively to our high-dependency unit for observation for $24 \mathrm{~h}$. Mean hospital

\section{TABLE 2 Summary of oesophageal physiology}

\begin{tabular}{lc} 
Lower oesophageal sphincter & \\
Pressure $\mathrm{mmHg}$ & $24.6 \pm 14.2$ \\
Length $\mathrm{cm}$ & $2.8 \pm 0.7$ \\
Mean distal peristaltic amplitude $\mathrm{mmHg}$ & $64.3 \pm 20.4$ \\
Peristalsis & \\
$\quad$ Normal & 14 \\
Abnormal & $2^{\#}$ \\
Reflux indices & \\
Acid exposure \% & $12.6 \pm 7.3$ \\
DeMeester score & $49.5 \pm 27.9$ \\
Oesophageal volume exposure \% & $1.3 \pm 0.4$ \\
Total reflux events & $66 \pm 27$ \\
Proximal reflux events & $23 \pm 15$ \\
\hline
\end{tabular}

Data are presented as mean \pm sd or $n .{ }^{*}$ : nonspecific dysmotility and diffuse oesophageal spasm. stay was $2.6 \pm 0.9$ days; longer stays were due to post-operative pain (in two patients with PEG fistulae repair), peri-operative dysphagia (one patient), a return to theatre or difficulty arranging transport home.

\section{Morbidity and mortality}

There were no deaths or serious post-operative complications. Two patients developed post-operative dysphagia. One of these patients returned to theatre the following day and underwent a laparoscopy and minor revision of fundoplication, and subsequently made an uneventful recovery. In the other patient, barium swallow revealed no significant blockage and symptoms subsequently resolved spontaneously.

\section{Overall satisfaction with fundoplication}

Overall, 15 out of 16 patients reported being satisfied at 6 weeks and 15 out of 16 patients reported satisfaction at 6 months. At 6 weeks one patient was unsatisfied due to dysphagia. At 6 months, one patient was unsatisfied due to pain at the site of their PEG fistula and abdominal bloating.

\section{Quality of life}

There was a statistically significant improvement in symptoms and quality of life scores over the first 6 months post-fundoplication. Kolmogorov-Smirnov analysis revealed the questionnaire data to be normally distributed. Questionnaires were completed by 15 out of 16 patients. One patient, despite reporting high levels of satisfaction with their result, did not wish to spend time completing these questionnaires. Patient symptom and quality of life questionnaire scores are summarised in table 3.

\section{RSI questionnaire}

Pre-fundoplication RSI was positive in eight out of 15 patients, and this decreased to three out of 15 being positive for RSI by 6 weeks and two out of 15 being positive at 6 months. The twoway ANOVA revealed a statistically significant improvement in RSI score over the three time-points $(p<0.001)$. Post-test Bonferroni correction revealed a statistically significant improvement in the mean \pm SD RSI score from $14 \pm 7.1$ pre-operatively to $6.7 \pm 7.9$ at 6 weeks post-fundoplication $(p=0.021)$ and $5.9 \pm 6.5$ at 6 months $(\mathrm{p}=0.003)$ (fig. 1a). The Bonferroni correction did not show a statistically significant difference between RSI scores at 6 weeks and 6 months.

\begin{tabular}{lccc} 
TABLE 3 & $\begin{array}{l}\text { Summary of symptom and quality of life } \\
\text { questionnaire scores }\end{array}$ \\
& Pre-operative & $\mathbf{6}$ weeks & $\mathbf{6}$ months \\
\hline DeMeester & $3.7 \pm 1.7$ & $1.5 \pm 1.6$ & $1.2 \pm 0.8$ \\
RSI & $14 \pm 7.1$ & $6.7 \pm 7.9$ & $5.9 \pm 6.5$ \\
GIQLI & $96.5 \pm 34.4$ & $105.1 \pm 27.6$ & $112.4 \pm 22.4$ \\
GIQLI subsets & & & \\
$\quad$ Symptoms & $49.7 \pm 10.5$ & $56.9 \pm 9.1$ & $58.7 \pm 7.6$ \\
$\quad$ Functional & $51.9 \pm 19.2$ & $54 \pm 19.2$ & $59.1 \pm 13.1$ \\
\hline
\end{tabular}

Data are presented as mean \pm SD. RSI: Reflux Symptom Index; GIQLI: Gastrointestinal Quality of Life Index. 

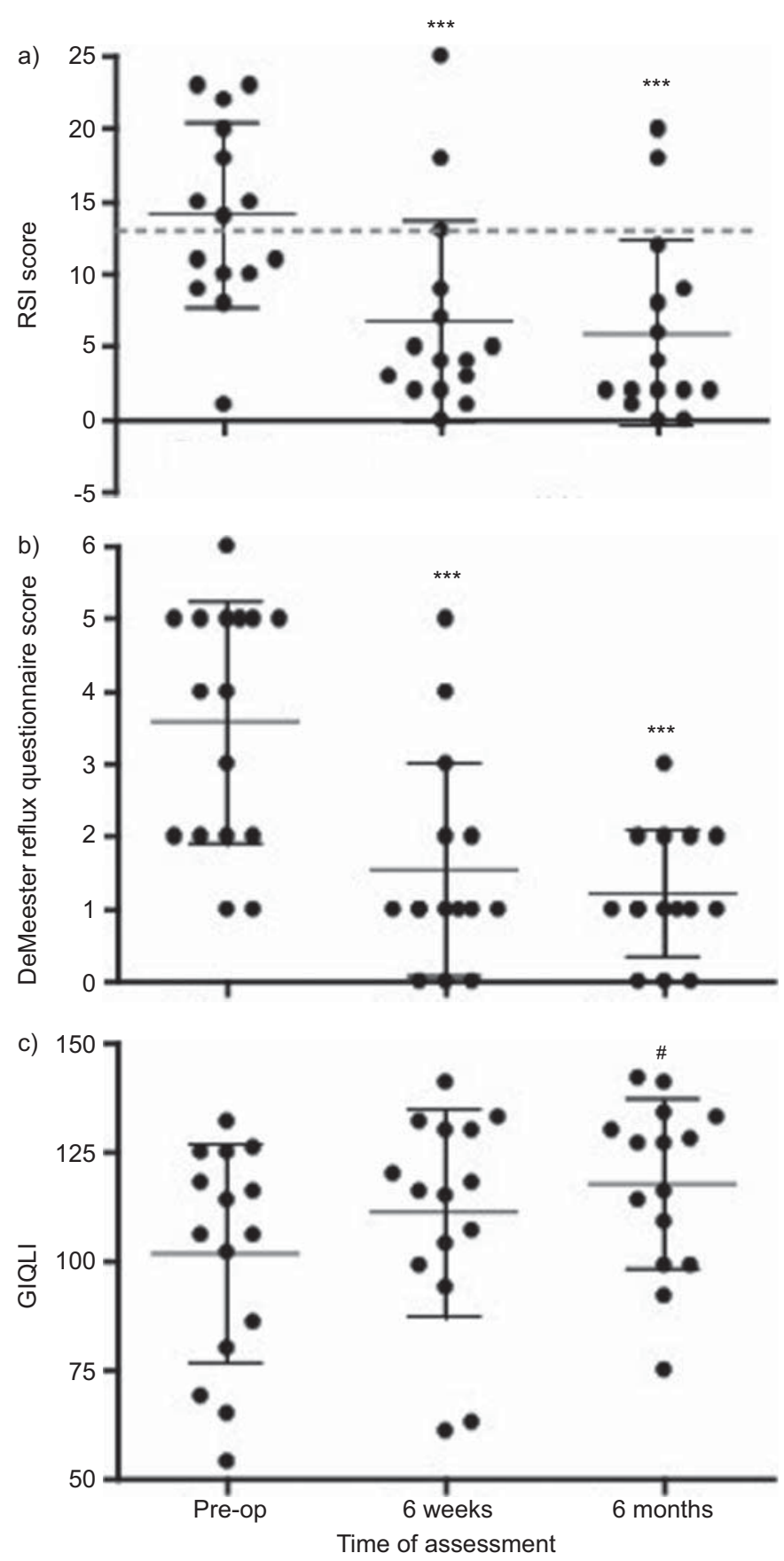

FIGURE 1. a) Reflux Symptom Index (RSI) score, b) DeMeester Reflux Questionnaire Score and c) Gastro-intestinal Quality of Life Index (GIQLI) score over the first 6 months post-fundoplication. The dotted line indicates a score of 13, the cut-off for a normal/abnormal score. Horizontal lines represent the mean and error bars represent the standard deviation. Pre-op: pre-operative. ${ }^{* \star *}: p<0.001$ compared to pre-op; ${ }^{\#}: \mathrm{p}=0.008$ compared to pre-op.

\section{DeMeester reflux questionnaire score}

The two-way ANOVA revealed a statistically significant improvement in DeMeester Reflux Questionnaire score over the three time-points $(p<0.001)$. Post-test Bonferroni correction revealed a statistically significant improvement in the mean $\pm \mathrm{SD}$ DeMeester questionnaire score from $3.7 \pm 1.7$ pre-operatively to $1.5 \pm 1.6$ at 6 weeks post-fundoplication $(p=0.012)$ and $1.2 \pm 0.8$ at 6 months $(p=0.003)$ (fig. $1 b)$. The Bonferroni correction did not show a statistically significant difference between DeMeester questionnaire scores at 6 weeks and 6 months.

\section{GIQLI}

The two-way ANOVA revealed a statistically significant improvement in RSI score over the three time-points $(p=0.008)$. Post-test Bonferroni correction revealed a statistically significant improvement in the mean \pm SD GIQLI score from $96.5 \pm 34.4$ preoperatively to $112.4 \pm 22.4$ at 6 months $(p=0.036)$ (fig. 1c). The Bonferroni correction did not show a statistically significant difference between GiQLI scores pre-operatively and at 6 weeks (mean \pm SD score 105.1 \pm 27.6$)$, or at 6 weeks or 6 months $(p=0.1)$.

\section{GIQLI sub-analysis}

\section{Symptoms}

The two-way ANOVA revealed a statistically significant improvement in symptom score from our GIQLI sub-analysis score over the three time-points $(\mathrm{p}<0.001)$. Post-test Bonferroni correction revealed a statistically significant improvement in mean \pm SD symptom score from our GIQLI sub-analysis from $49.7 \pm 10.5$ pre-operatively to $56.9 \pm 9.1$ at 6 weeks post-fundoplication $(p=0.03)$ and $58.7 \pm 7.6$ at 6 months $(p=0.006)$. The Bonferroni correction did not show a statistically significant difference between symptom score from our GIQLI sub-analysis at 6 weeks and 6 months.

\section{Functional}

The two-way ANOVA revealed a statistically significant improvement in functional score from our GIQLI sub-analysis over the three time-points $(p=0.036)$. Post-test Bonferroni correction did not reveal which pairs reached statistical significance in their improvement in mean $\pm S D$ functional score from our GIQLI sub-analysis score from $51.9 \pm 19.2$ pre-operatively to $54 \pm 19.2$ at 6 weeks post-fundoplication and $59.1 \pm 13.1$ at 6 months $(p=0.09)$, although there was a mean improvement of 7.2 points from the pre-operative score to the score at 6 months. There was a trend to significance from the pre-operative to the 6month score $(p=0.09)$ and from the 6-week to the 6-month score $(\mathrm{p}=0.11)$.

\section{Body mass index}

Kolmogorov-Smirnov analysis revealed this data to be normally distributed. Mean \pm SD BMI significantly decreased from $23.8 \pm$ $4.4 \mathrm{~kg} \cdot \mathrm{m}^{-2}$ pre-fundoplication to $22.6 \pm 4.6 \mathrm{~kg} \cdot \mathrm{m}^{-2}$ at 6 months post-fundoplication ( $\mathrm{p}=0.01)$ (fig. 2).

\section{Lung function}

Pre-fundoplication, nine patients had no evidence of BOS, whilst the remaining seven patients had BOS 0p (a new grade of BOS created in 2002 to denote "early BOS") $(n=1)$, BOS score $1(n=2)$, BOS $2(n=1)$ and BOS $3(n=3)$. Two patients had a worsening BOS score from BOS 0 to 1 and BOS 2 to 3 . Despite a slowing rate of decline, the patient who deteriorated from BOS 2 to 3 died 482 days post-fundoplication from respiratory failure. The patient with BOS $0 \mathrm{p}$ had a reversal of this to BOS 0 . All other patients remained stable.

Patients were followed up for a mean of $476 \pm 180$ days postfundoplication. FEV1 was similar pre-fundoplication $(2.4 \pm$ $0.97 \mathrm{~L})$ and post-fundoplication $(2.4 \pm 0.71 \mathrm{~L})(\mathrm{p}=0.08)$. 


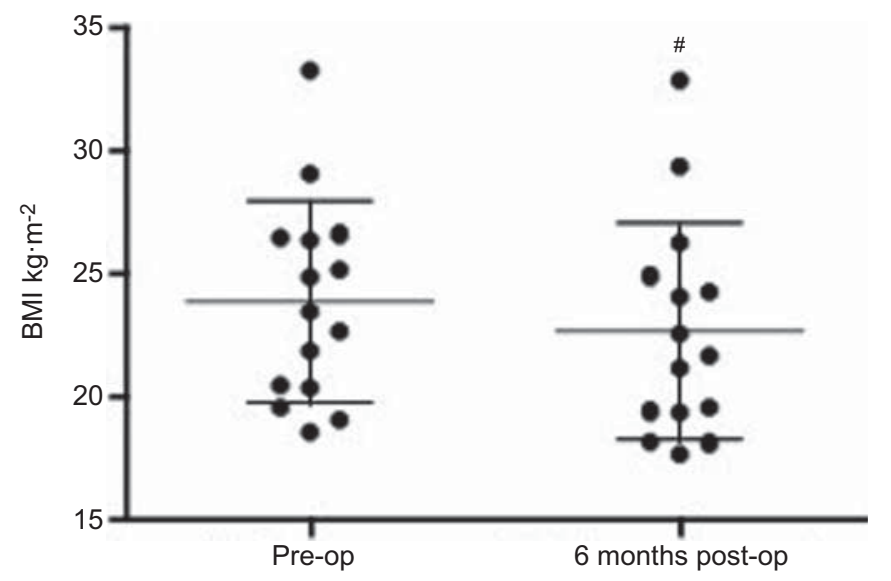

FIGURE 2. Body mass index (BMI) score pre-operatively (pre-op) and at 6 months post-fundoplication (post-op). Horizontal lines represent the mean and error bars represent the standard deviation. ${ }^{*}: p=0.001$ compared with pre-op.

Eight patients were operated on for deteriorating lung function. Of these eight, one patient had a reversal of BOS, two had a stabilisation of lung function and five had a decrease in the rate of deterioration. Kolmogorov-Smirnov analysis revealed this data to be normally distributed. In the eight patients operated on for deteriorating lung function, there was a statistically significant decrease in the rate of decline of FEV1 per month postfundoplication from a mean change $\pm S D$ of $-96.7 \pm 87.3 \mathrm{~mL}$. month $^{-1}$ pre-fundoplication to $+9.5 \pm 26.5 \mathrm{~mL} \cdot \mathrm{month}^{-1}$ post-fundoplication $(p=0.008)$ (fig. 3$)$. Individual traces are shown in figure 4 .

\section{DISCUSSION}

This study demonstrates that laparoscopic fundoplication in a transplant setting is safe. Patients reported a high level of satisfaction with the results of surgery at 6 weeks and 6 months. This study also demonstrated that, in this specialised patient population, laparoscopic anti-reflux surgery is effective in

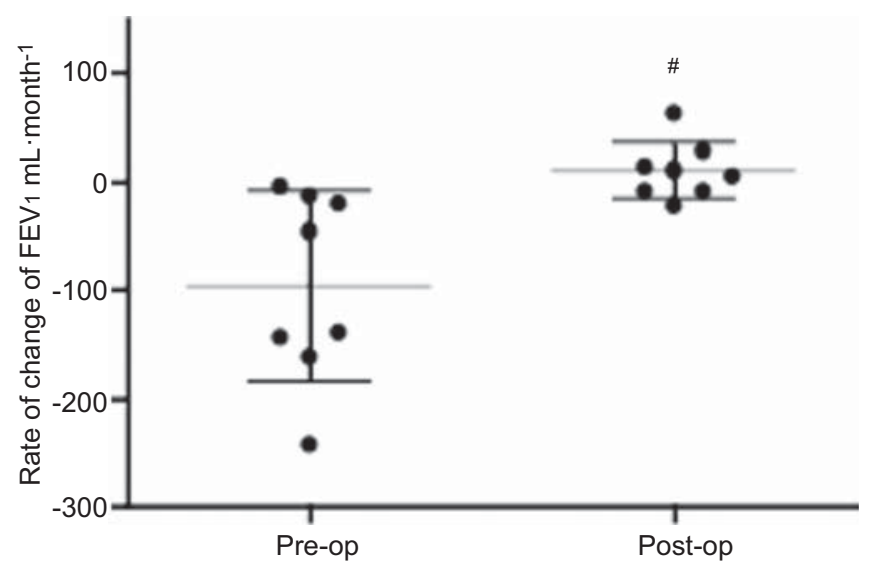

FIGURE 3. Rate of change of forced expiratory volume in $1 \mathrm{~s}$ (FEV1) pre- and post-fundoplication (pre- and post-op) in patients with deteriorating lung function Horizontal lines represent the mean and error bars the standard deviation. \#: $p=0.008$ compared with pre-op. reducing symptoms of GORD and improves quality of life. Our study also supports the possibility that fundoplication may impact positively on the loss of lung function seen in BOS.

These findings are important as there is little knowledge regarding laparoscopic fundoplication in these patients, and such surgery could potentially have negative effects. Our data demonstrating improvements in symptoms and quality of life are, therefore, reassuring. More speculatively, the reduction of decline in lung function observed in this open study supports the theory that fundoplication may protect the lung allograft from microaspiration injury, and suggests the need for further trials.

There is no consensus regarding fundoplication in lung transplant recipients [19]. Small series of fundoplication have been reported in patients with end-stage lung disease [20, 21]. Not all these patients will undergo transplant and there are significant risks associated with performing this procedure in patients with very poor lung function. We have adopted a pragmatic approach, operating in the post-transplant period on patients with symptomatic reflux and those with evidence of reflux and deteriorating lung function. Based on the available transplant evidence, laparoscopic Nissen fundoplication was favoured in our practice [22].

In the study of safety from Duke University, compared with the nontransplant population, there were no significant differences in operative time and blood loss [23]. Our study has comparable intra-operative data and no patients in our series have needed conversion to an open operation. No intra-operative or perioperative deaths have been reported by the Duke University group [5, 23, 24], although, recently, one post-fundoplication death has been reported [25]. We have experienced no mortality to date and no major complications were encountered. The Duke group have reported increased length of stay in the transplant population and a higher readmission rate, due to transplant comorbidity [23]. Our results are comparable with this experience. The long post-operative stay may be partially explained by the fact that transplant patients have to travel greater distances than a local population. Overall, our results suggest that laparoscopic fundoplication is safe in selected lung transplant recipients.

Over the last $20 \mathrm{yrs}$, quality of life assessments have been established as end-point outcomes. The GIQLI questionnaire has been recommended by the European Association for Endoscopic Surgery for the assessment of quality of life after fundoplication [26]. The DeMeester reflux questionnaire is validated to assess reflux symptoms and the RSI has been validated in nontransplant patients as a marker of extra-oesophageal reflux [13], and has been used to assess the effects of fundoplication on extraoesophageal reflux $[27,28]$.

In nontransplant patients, fundoplication has been shown to ameliorate reflux symptoms and improve quality of life [29]. This study showed that, in lung transplant recipients, there was an improvement in typical reflux symptoms. Although this may be expected, it has also shown an improvement in quality of life post-fundoplication, despite the high prevalence of foregut dysfunction in this population [11]. Our sub-analysis of the data showed that improvement in quality of life occurs via both amelioration of symptoms and improved social functioning. 

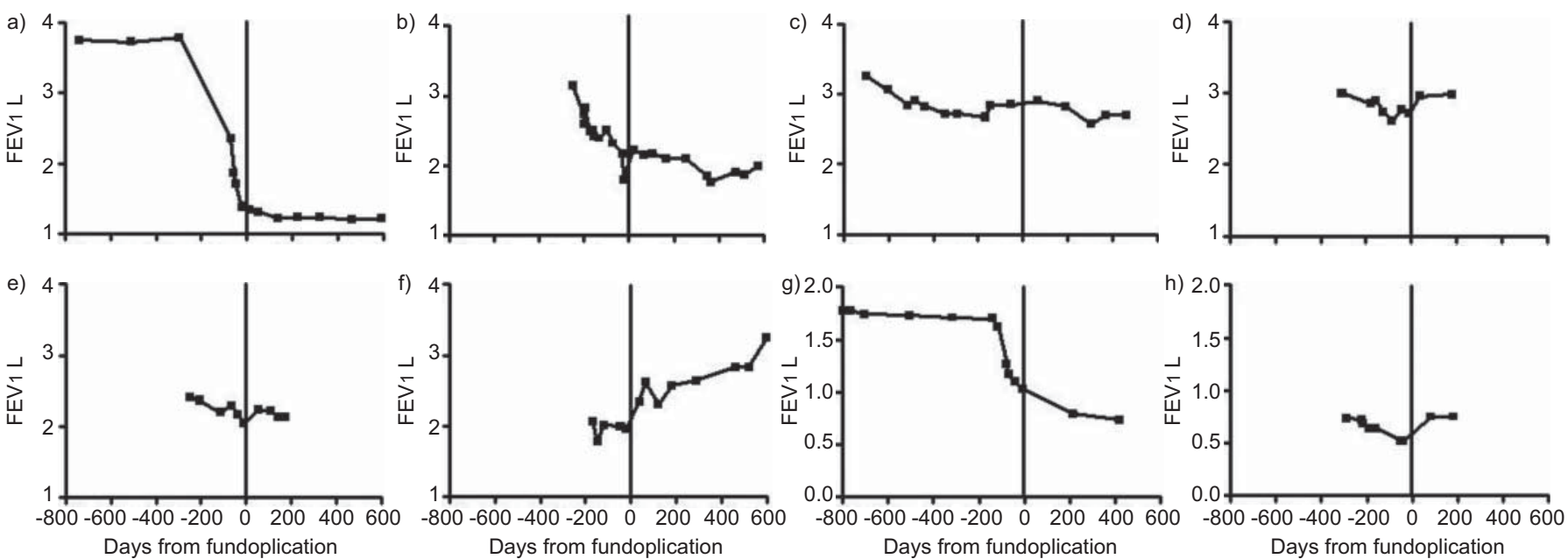

FIGURE 4. Changes in of forced expiratory volume in $1 \mathrm{~s}(\mathrm{FEV} 1)$ over time pre- and post-fundoplication in patients with deteriorating lung function

Questionnaires designed for the assessment of extra-oesophageal reflux have not previously been used in lung transplant recipients. Our finding of improvement in extra-oesophageal reflux symptoms in lung transplant recipients after fundoplication is, therefore, novel. These symptoms include cough and hoarseness, which can be caused by extra-oesophageal reflux, but may also represent primary respiratory symptoms. This finding further supports the theory that these patients experience laryngopharyngeal reflux $[13,27]$, which may precede microaspiration. It is unknown how the evolving changes in the lung transplant and BOS may affect extra-oesophageal reflux symptoms, but we believe improvements are possibly attributable to fundoplication.

The Melbourne group's study of fundoplication in lung transplantation described a decrease in mean BMI from $23 \mathrm{~kg} \cdot \mathrm{m}^{-2} 6$ months pre-operatively to $21 \mathrm{~kg} \cdot \mathrm{m}^{-2} 6$ months postoperatively. The current study's results are similar, with a decrease in mean BMI from $23.8 \mathrm{~kg} \cdot \mathrm{m}^{-2}$ to $22.6 \mathrm{~kg} \cdot \mathrm{m}^{-2} 6$ months post-operatively. The significance of this is unknown, but, in selected patients, post-fundoplication dietary advice and intervention may have an important role.

The Duke University Transplant Group has published several papers [5, 23, 24, 30, 31], each an update of a continuing programme, with results suggesting that anti-reflux surgery may lead to increased survival and improved lung function posttransplantation [5]. Our study was not designed to assess the impact of fundoplication on lung function. In our series, mean FEV1 did not deteriorate post-fundoplication. Those patients operated on for deteriorating lung function underwent a statistically significant reduction in the loss of lung function, and one patient had a reversal of a subtle defect in lung function.

Our current study has several limitations. The numbers involved were small and patients had a variety of indications for surgery. Fundoplication was performed at different times after transplant and no patients were operated on within 90 days of transplant, the suggested optimum time for intervention [5], although this study did not seek to define an optimum time for intervention. No control group was analysed and the study was not randomised. Further studies could include a focus on the effects of early fundoplication (within 90 days) on allograft function and long-term survival.

Almost all the evidence supporting fundoplication post-lung transplant originates from a single centre and only three other centres have published case series. Based on this evidence, we have tried to develop a series of pragmatic indications for those to be offered surgical interventions. The improvement in GORD symptoms and quality of life in these patients suggests that the developing indications for fundoplication post-lung transplant may include symptomatic GORD in fit patients. The reduction in deterioration of lung function post-fundoplication further supports a possible role of this therapy in the prevention of BOS, but further evidence is required, including formal trials. Our study suggests that, with careful design, such studies are possible and can be safe in an extended series of patients.

\section{SUPPORT STATEMENT}

A.G.N. Robertson received funding from the European Society for Organ Transplantation and the British Lung Foundation; P.A. Corris and C. Ward received funding from the Medical Research Council.

\section{STATEMENT OF INTEREST}

None declared.

\section{ACKNOWLEDGEMENTS}

We would like to thank C. Hannah (Freelance Art Director, Glasgow, UK) for our illustrations.

\section{REFERENCES}

1 Belperio JA, Weigt SS, Fishbein MC, et al. Chronic lung allograft rejection: mechanisms and therapy. Proc Am Thorac Soc 2009; 6: 108-121.

2 Robertson AGN, Griffin SM, Murphy D, et al. Targeting allograft injury and inflammation in the management of post-lung transplant bronchiolitis obliterans syndrome. Am J Transplant 2009; 9: 1272-1278

3 D'Ovidio F, Keshavjee S. Gastroesophageal reflux and lung transplantation. Dis Esophagus 2006; 19: 315-320.

4 Robertson AGN, Ward C, Pearson J, et al. Longitudinal changes in gastro-oesophageal reflux from three months to six months post lung transplantation. Thorax 2009; 64: 1005-1007. 
5 Cantu E 3rd, Appel JZ 3rd, Hartwig MG, et al. Maxwell Chamberlain Memorial Paper. Early fundoplication prevents chronic allograft dysfunction in patients with gastroesophageal reflux disease. Ann Thorac Surg 2004; 78: 1142-1151.

6 Stovold R, Forrest IA, Corris PA, et al. Pepsin, a biomarker of gastric aspiration in lung allografts: a putative association with rejection. Am J Respir Crit Care Med 2007; 175: 1298-1303.

7 Blondeau K, Mertens V, Vanaudenaerde BA, et al. Gastrooesophageal reflux and gastric aspiration in lung transplant patients with or without chronic rejection. Eur Respir J 2008; 31: 707-713.

8 D'Ovidio F, Mura M, Tsang M, et al. Bile acid aspiration and the development of bronchiolitis obliterans after lung transplantation. J Thorac Cardiovasc Surg 2005; 129: 1144-1152.

9 McKenna D, Beverstein G, Gould J. Gastrointestinal symptoms and patient satisfaction more than 1 year after laparoscopic Nissen fundoplication. Surg Endosc 2011; 25: 1797-1801.

10 Hartwig MG, Appel JZ, Davis RD. Antireflux surgery in the setting of lung transplantation: strategies for treating gastroesophageal reflux disease in a high-risk population. Thorac Surg Clin 2005; 15: 417-427.

11 Robertson AGN, Ward C, Pearson JP, et al. Lung transplantation, gastro-esophageal reflux and fundoplication. Ann Thorac Surg 2010; 89: 653-660.

12 DeMeester T, Wang CI, Wernly JA, et al. Technique, indication, and clinical use of 24 hour esophageal $\mathrm{pH}$ monitoring. J Thorac Cardiovasc Surg 1980; 79: 656-670.

13 Belafsky PC, Postma GN, Koufman JA, et al. Validity and reliability of the reflux symptom index (RSI). J Voice 2002; 16: 274-277.

14 Eypasch E, Williams JI, Wood-Dauphinee S, et al. Gastrointestinal Quality of Life Index: development, validation and application of a new instrument. Br J Surg 1995; 82: 216-222.

15 Wanger J, Clausen JL, Coates A, et al. Standardisation of the measurement of lung volumes. Eur Respir J 2005; 26: 511-522.

16 Estenne M, Maurer JR, Boehler A, et al. Bronchiolitis obliterans syndrome 2001: an update of the diagnostic criteria. J Heart Lung Transplant 2002; 21: 297-310.

17 Estenne M, Hertz MI. Bronchiolitis obliterans after human lung transplantation. Am J Respir Crit Care Med 2002; 166: 440-444.

18 Fisher AJ, Rutherford RM, Bozzino J, et al. The safety and efficacy of total lymphoid irradiation in progressive bronchiolitis obliterans syndrome after lung transplantation. Am J Transplant 2005; 5: 537-543.
19 Robertson AG, Shenfine J, Ward C, et al. A call for standardization of antireflux surgery in the lung transplantation population. Transplantation 2009; 87: 1112-1114.

20 Linden PA, Gilbert RJ, Yeap BY, et al. Laparoscopic fundoplication in patients with end-stage lung disease awaiting transplantation. J Thorac Cardiovasc Surg 2006; 131: 438-446.

21 Gasper WJ, Sweet MP, Hoopes C, et al. Antireflux surgery for patients with end-stage lung disease before and after lung transplantation. Surg Endosc 2008; 22: 495-500.

22 Griffin SM, Robertson AGN. Prophylactic antireflux surgery in lung transplantation, In: Ferguson M, ed. Difficult Decisions in Thoracic Surgery: An Evidence Based Approach. 2nd Edn. Heidelberg, Springer Verlag, 2010.

23 O'Halloran EK, Reynolds JD, Lau CL, et al. Laparoscopic Nissen fundoplication for treating reflux in lung transplant recipients. J Gastrointest Surg 2004; 8: 132-137.

24 Balsara KR, Cantu E, Bush EL, et al. Early fundoplication reduces the incidence of chronic allograft dysfunction in patients with gastroesophageal reflux disease. J Heart Lung Transplant 2008; 27: S125.

25 Burton PR, Button B, Brown W, et al. Medium-term outcome of fundoplication after lung transplantation. Dis Esophagus 2009; 22: 642-648.

26 Korolija D, Sauerland S, Wood-Dauphinee S, et al. Evaluation of quality of life after laparoscopic surgery: evidence-based guidelines of the European Association for Endoscopic Surgery. Surg Endosc 2004; 18: 879-897.

27 Westcott CJ, Hopkins MB, Bach K, et al. Fundoplication for laryngopharyngeal reflux disease. J Am Coll Surgeons 2004; 199: 23-30.

28 Iqbal $\mathrm{M}$, Batch $\mathrm{AJ}$, Moorthy $\mathrm{K}$, et al. Outcome of surgical fundoplication for extra-oesophageal symptoms of reflux. Surg Endosc 2009; 23: 557-561.

29 Yano F, Sherif AE, Turaga K, et al. Gastrointestinal quality of life in patients after anti reflux surgery. Dis Esophagus 2009; 22: 177-184.

30 Lau CL, Palmer SM, Howell DN, et al. Laparoscopic antireflux surgery in the lung transplant population. Surg Endosc 2002; 16: 1674-1678.

31 Davis RD Jr, Lau CL, Eubanks S, et al. Improved lung allograft function after fundoplication in patients with gastroesophageal reflux disease undergoing lung transplantation. I Thoracic Cardiovasc Surg 2003; 125: 533-542. 